Int. J. Electrochem. Sci., 12 (2017) 3916 - 3930

\title{
Effect of Pre-deformation on Microstructure and Pitting Corrosion Behavior of UNS S32205
}

\author{
Xu Si, Jun Wu, Yiwei Tang, Jin Li, Yiming Jiang ${ }^{*}$ \\ Department of Materials Science, Fudan University, Shanghai, 200433 \\ *E-mail: ymjiang@fudan.edu.cn
}

doi: $10.20964 / 2017.05 .44$

Received: 23 February 2017 / Accepted: 21 March 2017 / Published: 12 April 2017

\begin{abstract}
The present work studied the microstructure of strain-induced martensite (SIM) in a UNS S32205 DSS under different strains. The material was strained at room temperature from 0 to $30 \%$ and the change of microstructure in the duplex stainless steel was investigated by several characterization techniques, such as optical metallographic microscopy (OMM), energy dispersive spectroscopy (EDS), scanning and transmission electron microscopy (SEM), X-ray diffraction (XRD), magnetic properties measurements and HV hardness measurements. In addition, the effects of the SIM on the corrosion behavior in chloride solutions with different $\mathrm{pH}$ have been studied. The experimental results showed that the SIM, the magnetization saturation and the micro-hardness values increased as the pre-tensile strain increased from 0 to $30 \%$. The results also revealed that the pitting corrosion resistance was insensitive to the SIM. The pitting potential decreased in acid chloride solution at $\mathrm{pH} \approx 2$ (3.5 wt.\% $\mathrm{NaCl}+0.01 \mathrm{~mol} / \mathrm{L} \mathrm{HCl}$ ) with the increasing of the deformation, however, in $3.5 \mathrm{wt} . \% \mathrm{NaCl}$ solution and $\mathrm{pH} \approx 12(3.5 \mathrm{wt} . \% \mathrm{NaCl}+0.01 \mathrm{~mol} / \mathrm{L} \mathrm{NaOH})$, the pitting potential was hardly affected by the SIM.
\end{abstract}

Keywords: Duplex stainless steel, Strain induced martensite, Microstructure characterization, Pitting corrosion behavior

\section{$\underline{\text { FULL TEXT }}$}

(C) 2017 The Authors. Published by ESG (www.electrochemsci.org). This article is an open access article distributed under the terms and conditions of the Creative Commons Attribution license (http://creativecommons.org/licenses/by/4.0/). 